\title{
Safety and Efficacy of Remdesivir for the Treatment of COVID-19: A Systematic Review and Meta-Analysis
}

\begin{abstract}
Mohammad Tasavon Gholamhoseini ${ }^{1}$, Vahid Yazdi-Feyzabadi ${ }^{2,3}$, Reza Goudarzi ${ }^{1,3}$, and Mohammad Hossein Mehrolhassani ${ }^{4}$
${ }^{1}$ Health Services Management Research Center, Institute for Futures Studies in Health, Kerman University of Medical Sciences, Kerman, Iran; ${ }^{2}$ Health in Disasters and Emergencies Research Center, Institute for Futures Studies in Health, Kerman University of Medical Sciences, Kerman, Iran; ${ }^{3}$ Department of Health Management, Policy and Economics, Faculty of Management and Medical Information Sciences, Kerman University of Medical Sciences, Kerman, Iran.; ${ }^{4}$ Social Determinants of Health Research Center, Institute for Futures Studies in Health, Kerman University of Medical Sciences, Kerman, Iran
\end{abstract}

Corresponding author: Vahid Yazdi-Feyzabadi, Health in Disasters and Emergencies Research Center, Institute for Futures Studies in Health, Kerman University of Medical Sciences, Kerman, Iran; TEL: (+98) 9131995219; Fax: (+98) 31325415; email: v-yazdi@ kmu.ac.ir

Received, March 6, 2021; Revised, April 26, 2021; Accepted, May 15, 2021; Published, May17, 2021

ABSTRACT -- Purpose: To evaluate the safety and efficacy of remdesivir in adult patients with COVID-19. Methods: PubMed, Embase, Scopus, Web of Science, Cochrane Library, ClinicalTrials.gov, and medRxiv databases were searched using a search strategy tailored to each database. The Consolidated Standards of Reporting Trials (CONSORT) and Strengthening the reporting of observational studies in epidemiology (STROBE) checklists were used for the studies' qualitative assessment. The outcomes studied were mortality, all adverse events, serious adverse events, and clinical improvement. The quantitative synthesis was conducted using fixed and random effects models in the CMA 2.2. Heterogeneity was tested using the I-squared $\left(\mathrm{I}^{2}\right)$ measure. Results: In general, six studies, including five randomized controlled trials and one cohort study were found eligible. Comparison of the findings related to both groups receiving remdesivir (10-day remdesivir group) and placebo/control group showed that remdesivir treatment had no significant effect on mortality at day 14 of the treatment $(\mathrm{RR}=0.769 ; 95 \% \mathrm{CI}: 0.563-1.050 ; \mathrm{p}=0.098)$, and all adverse events ( $\mathrm{RR}=1.078$; 95\% CI: 0.908-1.279; $\mathrm{p}=0.392$ ). However, remdesivir had a significant effect on clinical improvement at day 14 compared to placebo/control $(\mathrm{OR}=1.447 ; 95 \% \mathrm{CI}: 1.005-2.085 ; \mathrm{p}=0.047)$ and reduced serious adverse events $(\mathrm{RR}=0.736$; 95\% CI: 0.611-0.887; $\mathrm{p}=0.001)$. Conclusion: Remdesivir has positive effects on clinical improvement, and reduction of the risk of serious adverse events. However, it does not influence the mortality at day 14 of treatment.

\section{INTRODUCTION}

In general, although for the treatment of COVID-19, several therapeutic agents with minor effects have been examined, no specific effective antiviral treatment has not been identified for (1). In addition, due to the limited accessibility to the recently introduced COVID-19 vaccines, (2) drugs with promising clinical outcomes are welcome. For this purpose, numerous drugs including remdesivir, favipiravir, bamlanivimab, dexamethasone with different effects on clinical improvement, mortality, duration of hospital stay (3-6), have been recommended (7-10).

The antiviral agent remdesivir was used as a direct-acting drug in the wake of the 2014 Ebola virus outbreak in West Africa (11). Clinical trial studies have also been performed to assess the different effects of this drug on COVID-19. One of the most notable outcomes evaluated in some studies was the mortality rates at 7,14 , and 28 days of therapy. The results of a randomized double-blind trial study suggested reduced mortalityfor the hospitalized patients with COVID-19 after 10-days of remdesivir therapy (12). In another similar study, however, the mortality rate in the remdesivir group was higher than in the placebo (13). Besides, a systematic analysis of a limited number of reports confirmed the beneficial effects of remdesivir $(1,6)$.

\footnotetext{
Abbreviation. CONSORT: consolidated reporting standards; STROBE: strengthening the reporting of observational studies in the epidemiology; RR: risk ratio; CI: confidence interval; OR: odds ratio
} 
Furthermore, the World Health Organization's Solidarity Trial (14) conducted the largest clinical trial to present the best proposed COVID-19 treatments. However, although their results demonstrated non-significant differences in the mortality rate for both remdesivir and the control groups, the FDA issued immediate approval for the antiviral drug (15). According to the FDA recommendations, adults and pediatric patients (over 12 years with more than $40 \mathrm{~kg}$ in weight) are eligible to receive this drug in hospitals. It is also affirmed that remdesivir is currently prescribing as one of the principal treatments for COVID-19 in approximately 50 countries (16).

Concerning the inconsistencies in the published results of the above-mentioned single studies, the present study was aimed to systematically review and meta-analyze the findings of investigated relevant individual studies to evaluate the safety and efficacy of remdesivir in adult patients with COVID-19. Furthermore, from the beginning of the pandemic, mall human studies have been published over time, however, no systematic review and meta-analysis has been found that includes all of these studies. Thus, this study is an updated systematic review and meta-analysis assessing the safety and efficacy of remdesivir in adult patients with COVID-19.

\section{METHODS}

\section{Search strategy and databases}

This is a systematic review and meta-analysis of studies found in PubMed, Embase, Scopus, Web of Science, Cochrane Library, ClinicalTrials.gov, and medRxiv from the outbreak of COVID-19 until October 31, 2020. Furthermore, this study described a PICO structure with several criteria (Population: Adult patients with COVID-19; Intervention: Remdesivir treatment; Comparison: Standard care or placebo; Outcomes: Safety and efficacy). All terms in were chosen using keywords relevant to $\mathrm{MeSH}$ and Emtree terms. Additionally, the search strategy based on each specific database was performed using a combination of COVID-19, remdesivir, safety, and efficacy keywords.

\section{Inclusion and exclusion criteria}

The following inclusion criteria were applied: studies in adults aged over 18 years with COVID-19, remdesivir as the main intervention, human populations, cohort and randomized controlled trials
(RCTs) designs, and English language studies. Available unpublished studies were also included. Research design articles, letters, and comments to editors were excluded.

\section{Quality assessment}

For the RCTs, quality assessment was performed using consolidated reporting standards (CONSORT) checklist consisting of 25 items that assess the quality of the RCTs research method. The minimum and maximum achievable scores inserted in this checklist ranged from 0 (low quality) to 25 (high quality). In addition, the strengthening the reporting of observational studies in epidemiology (STROBE) checklist was applied for observational cohort studies. There were 22 items with minimum and maximum scores equal to 0 and 44 , respectively. Eventually, studies with adequate scores entered into the meta-analysis (scores more than 13 and 16 according to the CONSORT and STROBE checklists, respectively). For scoring of each item included in the checklists, all required explanations were presented and then judged. For scoring of each item included in the checklists, all required explanations related to one study were read for several times and then were judged.

\section{Data extraction}

All data transferred to the Endnote software. Then, studies were selected independently by two authors, and data extracted from eligible studies. Also, the studies were checked by a third person if the reviewers disagreed. In the next stage, an Excel software-based form was designed. Then, we summarized the detailed data, including the first author's surname, title, the geographical location of the research, date published, study type, patients' groups, patients' age, sample size, intervention, comparison, and results.

\section{Outcome measures}

Among the various outcomes reported, we chose mortality, clinical improvement, all adverse events, and serious adverse events.

\section{Statistical analysis}

The effect estimation was in risk ratio (RR) for mortality at day 14 of treatment, all adverse events and serious adverse events, and odds ratios (OR) for clinical improvement at day 14 , with $95 \%$ confidence intervals (CI). The pooled effects size estimation was performed by a fixed-effect or random-effect model 
after heterogeneity results were assessed. Heterogeneity was also calculated using the $\mathrm{I}^{2}$ value.

\section{Sensitivity analysis}

Sensitivity analyses were conducted for at least two reasons. First, among the included studies, there was an unpublished study which was not peer-reviewed. Second, there was merely a large cohort study among the included studies versus mall RCTs. Thus, we separately assessed the results related to changes in clinical outcomes by excluding these studies. All data were also analyzed by the Comprehensive MetaAnalysis software (CMA 2.2).

\section{RESULTS}

In the primary search, 1223 reports were found in different databases from which six were eligible for our meta-analysis (Figure 1, Table 1).

\section{Mortality at day 14 of the treatment}

In general, five studies reported mortality at day 14 of the treatment. The random-effects model results indicated that the use of remdesivir had no effect on relative risk of mortality at day 14 of the treatment $(\mathrm{RR}=0.769$; 95\% CI:0.563-1.050; $\mathrm{p}=0.098$ ) (Figure 2 ). It was also observed that the heterogeneity of the studies was moderate at $\mathrm{I}^{2}=55 \%$. The results of the sensitivity analysis revealed when a single cohort study was dropped from the analysis and metanalysis was limited to RCTs, overall effect size for mortality at day 14 of the treatment is statistically unsignificant $(\mathrm{RR}=0.823$; 95\% CI: 0.578-1.172; $\mathrm{p}=0.280$ ).

\section{Clinical improvement at day 14}

Only two studies reported clinical improvement on day 14. The results of using the fixed-effect model showed that remdesivir therapies were associated with higher odds of clinical improvement (equal to $44.7 \%$; $\mathrm{p}<0.05)$ than the placebo group $(\mathrm{OR}=1.447$; 95\% CI: 1.005-2.085; $\mathrm{p}=0.047 ; \mathrm{I}^{2}=0 \%$ ) (Figure 3).

\section{All adverse events}

According to the search results, three studies reported some information related to adverse events. The most important adverse events obtained from these studies were: hypoalbuminemia, hypokalaemia, anemia, thrombocytopenia, increased total bilirubin, nausea, and headaches. The randomeffects model showed that remdesivir nonsignificantly increased (equal to $7.8 \%$ ) the risk of all adverse events in comparison with the placebo/control treatment $(\mathrm{RR}=1.078 ; 95 \% \mathrm{CI}$ : 0.908-1.279; $\mathrm{p}=0.392$ ) (Figure 4). In this section, there was a high degree of heterogeneity among studies $\left(\mathrm{I}^{2}=68 \%\right)$.

\section{Serious adverse events}

Four studies evaluated serious adverse events, including respiratory failure or acute respiratory distress syndrome, cardiopulmonary failure, pulmonary embolism, and COVID-19 recurrence. The results of the fixed-effect model determined that remdesivir significantly reduced the risk of serious adverse events compared to placebo/control (RR= $0.736 ; 95 \%$ CI: 0.611-0.887; $\mathrm{p}=0.001 ; \mathrm{I}^{2}=0 \%$ ) (Figure 5). In a sensitivity analysis excluding the unpublished and not peer-reviewed study conducted by Maffei and Sonia, the overall effect size for serious adverse events remained statistically significant with a reduced effect of $2 \%$ (RR:0.765; 95\% CI: 0.624-0.915; $\mathrm{p}=0.004$ ).

\section{DISCUSSION}

Remdesivir, as the first and only FDA-approved antiviral drug, received an emergency use authorization on May 1, 2020, for treating patients with COVID-19 at the acute phase (20). However, mall heterogeneities have been reported for remdesivir's effects on mortality rate, and adverse effects. Accordingly, this study aimed to assess the safety and efficacy of remdesivir compared with placebo/control in adult patients with COVID-19.

The meta-analysis of the risk ratio suggests that remdesivir (in comparison with placebo/control) had no significant effects on mortality at day 14 of treatment in patients receiving the drug for 10 days. Our results are not in agreement with those systematic reviews recently reported $(21,22)$. Wang et al. pooled only two studies and found that remdesivir was significantly associated with a reduction in mortality at day 14 of treatment for patients with severe COVID-19 $(\mathrm{RR}=0.64$; 95\% CI: 0.44-0.94) (21). Besides, Sarfraz et al. confirmed that remdesivir significantly reduced mortality on day 14 of the treatment (95\% CI: $0.45-0.82 ; \mathrm{p}=0.001$ ) (22). In contrast, systematic review of Juul et al. suggested that remdesivir had no significant effects on all-cause mortality at day 28 of treatment compared with placebo/control $(\mathrm{RR}=0.74 ; 95 \% \mathrm{CI}$ : $0.40-1.37 ; p=0.34)(1)$, which was consistent with our results. These discrepancies can be due to at least two reasons. First, we included one more study than 


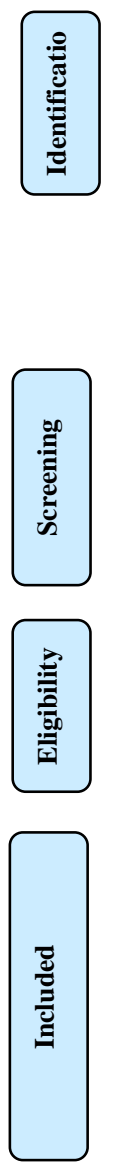

Database (number of reports): PubMed (66), Embase (189), Scopus (651), Web of Sciense (194), Cochrane library (71), ClinicalTrials.gov (13) and medRxiv (39)
Additional records identified through other sources $(\mathrm{n}=1)$

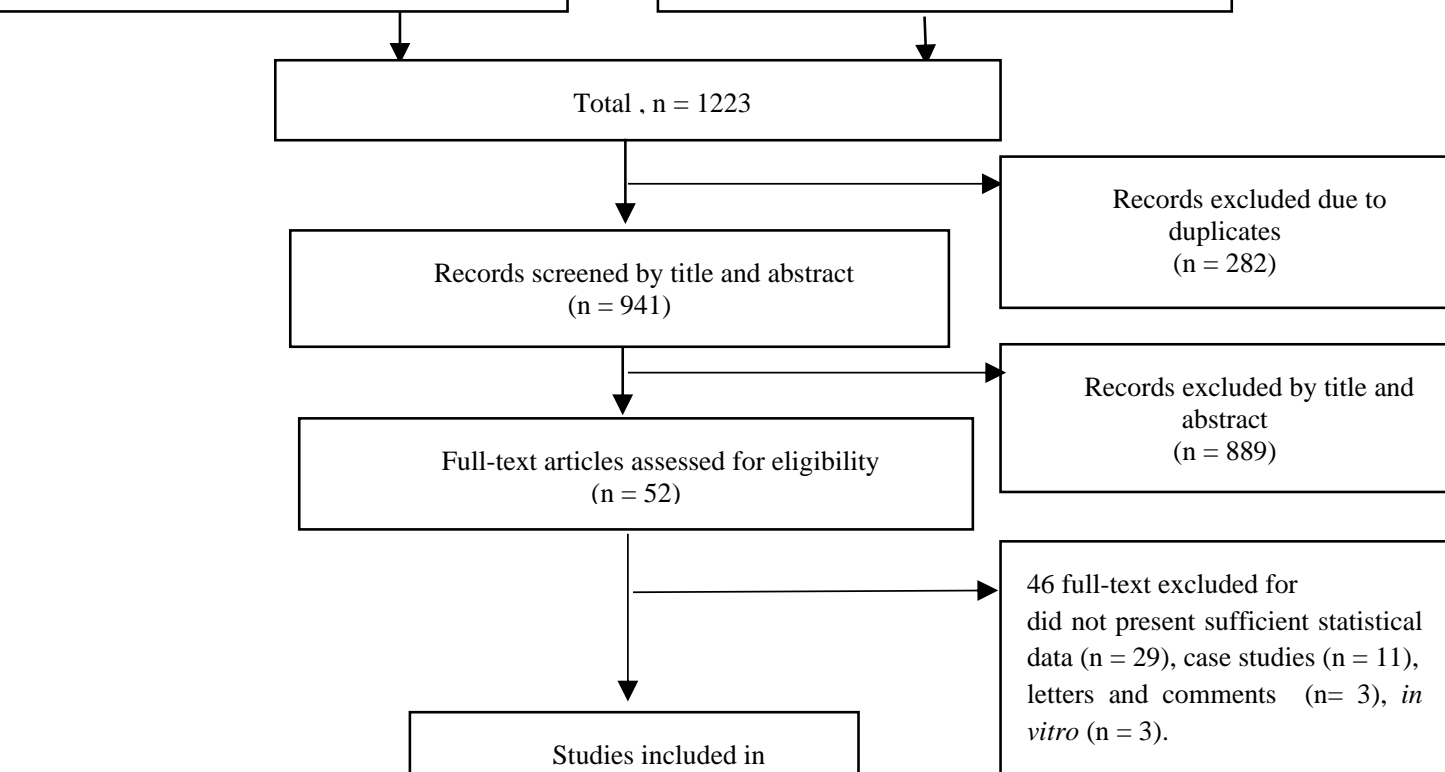

Figure 1. PRISMA flow chart

Table 1. Description of characteristics of included studies

\begin{tabular}{|c|c|c|c|c|c|c|c|c|c|}
\hline \multirow[b]{2}{*}{ Author } & \multirow[b]{2}{*}{$\begin{array}{l}\text { Study } \\
\text { type }\end{array}$} & \multirow[b]{2}{*}{ Design } & \multirow[b]{2}{*}{$\begin{array}{l}\text { Intervention } \\
\text { analyzed }\end{array}$} & \multirow[b]{2}{*}{$\mathbf{n}$} & \multicolumn{4}{|c|}{ Outcomes } & \multirow[b]{2}{*}{$\begin{array}{l}\text { Quality } \\
\text { assessment }\end{array}$} \\
\hline & & & & & Mortality & $\begin{array}{l}\text { clinical } \\
\text { improvement }\end{array}$ & $\begin{array}{l}\text { All } \\
\text { adverse } \\
\text { events }\end{array}$ & $\begin{array}{l}\text { Serious } \\
\text { adverse } \\
\text { events }\end{array}$ & \\
\hline \multirow{2}{*}{$\begin{array}{l}\text { Spinner } \\
(17)\end{array}$} & \multirow[b]{2}{*}{$\mathrm{RCT}$} & \multirow{2}{*}{$\begin{array}{l}\text { Randomized, } \\
\text { open-label, } \\
\text { clinical trial }\end{array}$} & Remdesivir & 200 & $*$ & * & & $*$ & \\
\hline & & & Placebo & 384 & $*$ & $*$ & NR & $*$ & 23 \\
\hline \multirow{2}{*}{$\begin{array}{l}\text { Beigel } \\
(12)\end{array}$} & \multirow[b]{2}{*}{$\mathrm{RCT}$} & \multirow{2}{*}{$\begin{array}{l}\text { Randomized, } \\
\text { open-label, } \\
\text { clinical trial }\end{array}$} & Remdesivir & 541 & $*$ & \multirow[b]{2}{*}{ NR } & $*$ & $*$ & \multirow[b]{2}{*}{22} \\
\hline & & & Placebo & 521 & $*$ & & $*$ & $*$ & \\
\hline \multirow[b]{2}{*}{ Wang (13) } & \multirow[b]{2}{*}{$\mathrm{RCT}$} & \multirow{2}{*}{$\begin{array}{l}\text { Randomized, } \\
\text { open-label, } \\
\text { clinical trial }\end{array}$} & Remdesivir & 158 & * & * & $*$ & * & \multirow[b]{2}{*}{22} \\
\hline & & & Placebo & 78 & $*$ & $*$ & $*$ & $*$ & \\
\hline \multirow[b]{2}{*}{ Pan (14) } & \multirow[b]{2}{*}{$\mathrm{RCT}$} & \multirow{2}{*}{$\begin{array}{l}\text { Randomized, } \\
\text { open-label, } \\
\text { clinical trial }\end{array}$} & Remdesivir & 2743 & $*$ & \multirow[b]{2}{*}{ NR } & \multirow[b]{2}{*}{ NR } & \multirow[b]{2}{*}{ NR } & \multirow[b]{2}{*}{23} \\
\hline & & & Standard care & 2708 & $*$ & & & & \\
\hline \multirow{2}{*}{$\begin{array}{l}\text { Olender } \\
(18)\end{array}$} & \multirow{2}{*}{ Cohort } & \multirow[t]{2}{*}{ Retrospective } & Remdesivir & 312 & $*$ & \multirow{2}{*}{ NR } & \multirow{2}{*}{ NR } & \multirow{2}{*}{ NR } & \multirow{2}{*}{33} \\
\hline & & & Standard care & 818 & * & & & & \\
\hline \multirow{2}{*}{$\begin{array}{l}\text { Maffei } \\
\text { (19) }\end{array}$} & \multirow[b]{2}{*}{$\mathrm{RCT}$} & \multirow{2}{*}{$\begin{array}{l}\text { Randomized, } \\
\text { open-label, } \\
\text { clinical trial }\end{array}$} & Remdesivir & 193 & \multirow[b]{2}{*}{ NR } & & $*$ & $*$ & \\
\hline & & & Standard care & 200 & & NR & $*$ & $*$ & 14 \\
\hline
\end{tabular}

NR, not reported; *, outcome reported. 
meta-analysis conducted by Sarfraz et al. and three more studies than Wang et al. meta-analysis study. Thus, adding new studies changed the previous results. Second, a large sample interim study of WHO solidarity trial conducted by Pan et al. was included in our study with the most influential and weight on pooled estimation (14). That study also supports our results indicating no effect of remdesivir on mortality at day 14 of the treatment.

The sensitivity analysis results also illustrated that excluding the cohort study conducted by Olender et al. (18) had no effect on the results and consequently had no effect of remdesivir on mortality as a clinical outcome.

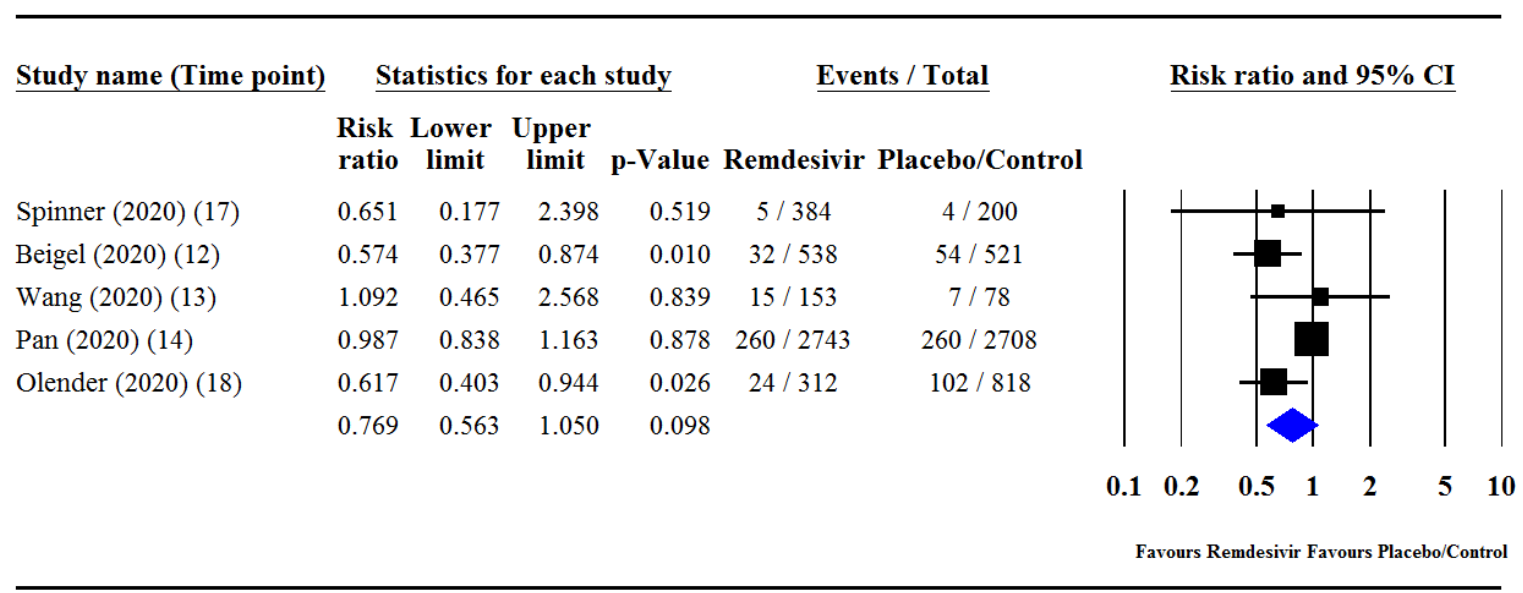

Figure 2. Meta-analysis of remdesivir versus placebo/control on mortality at day 14 of treatment

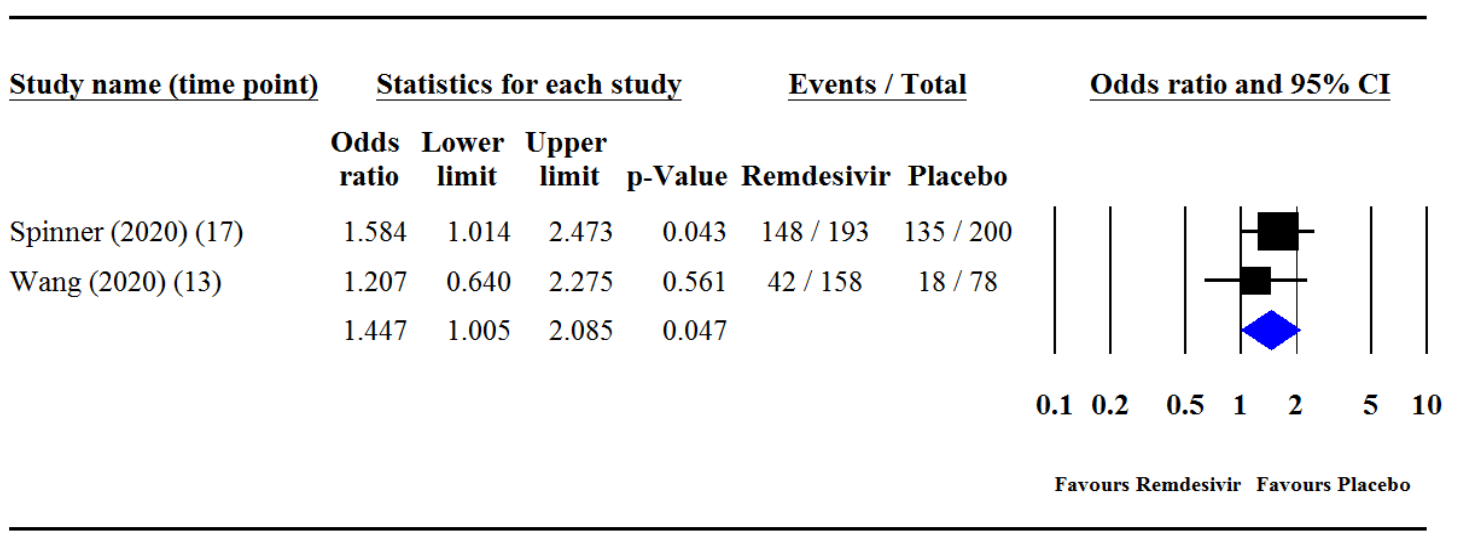

Figure 3. Meta-analysis of remdesivir versus placebo on clinical improvement at day 14 


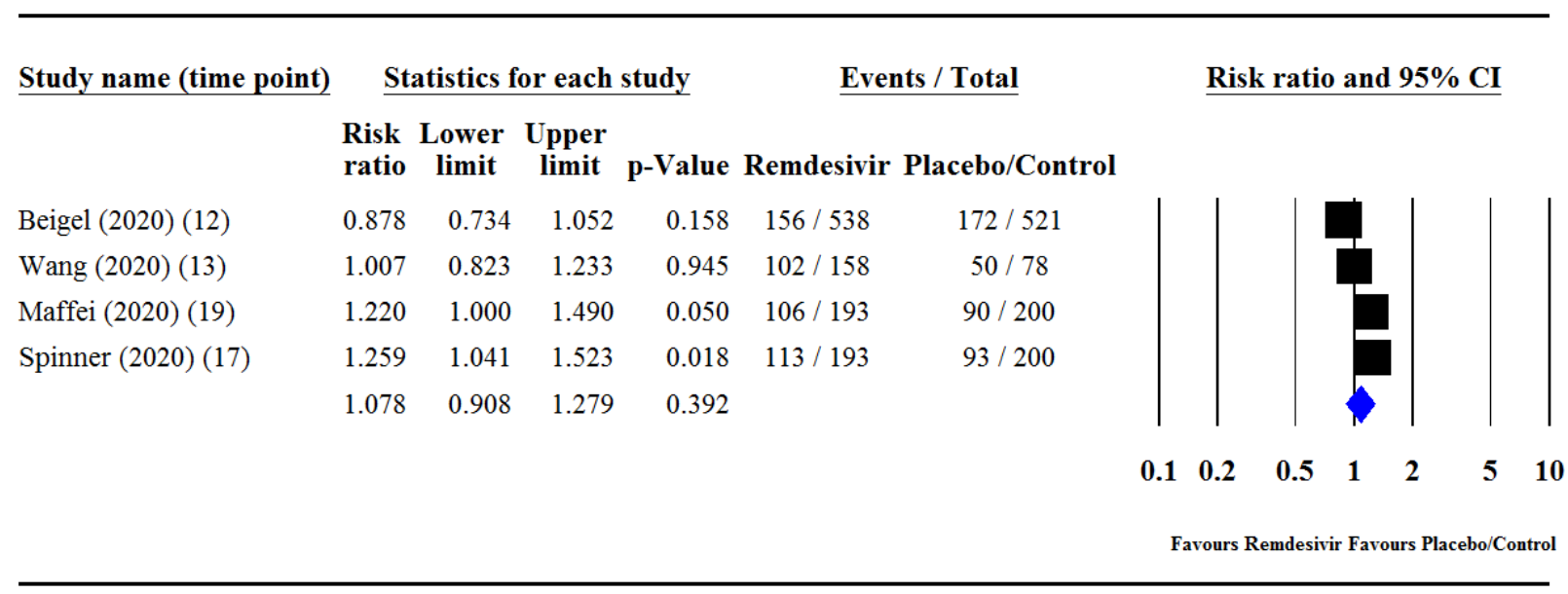

Figure 4. Meta-analysis of remdesivir versus placebo on all adverse events

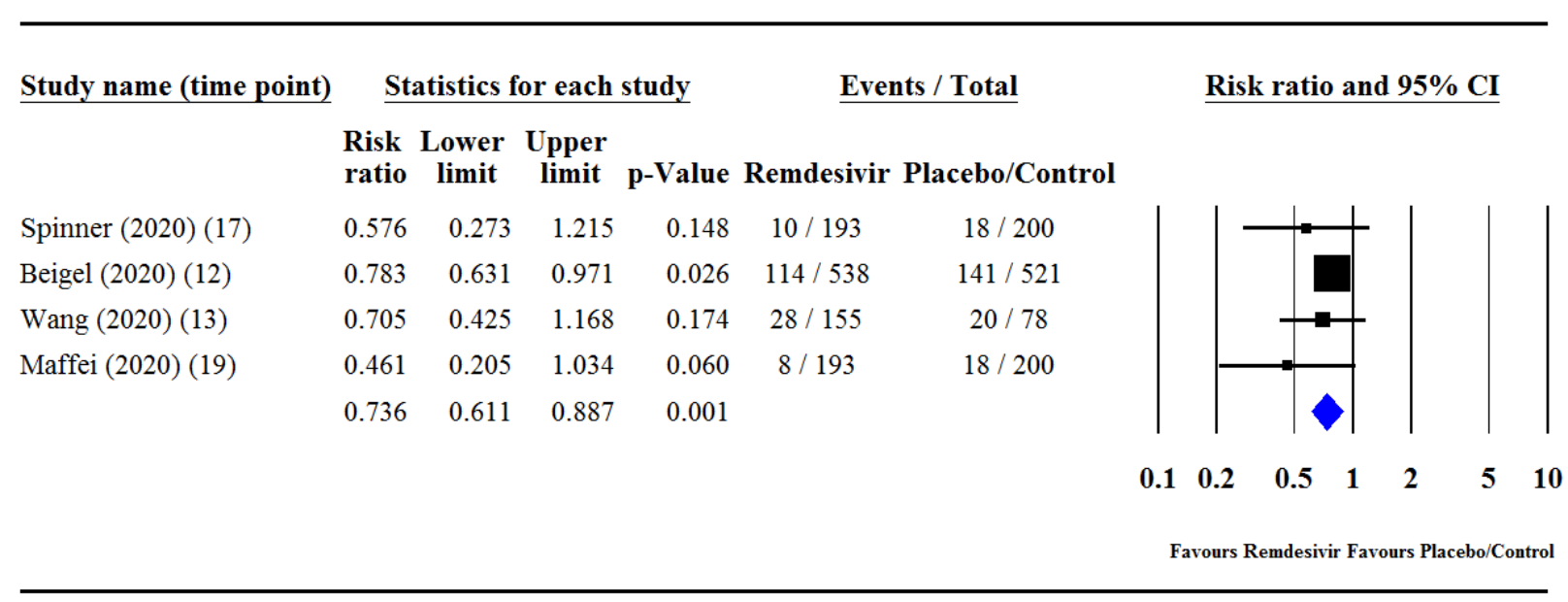

Figure 5. Meta-analysis of remdesivir versus placebo on serious adverse events

Regarding the clinical improvement, our results indicated that remdesivir was associated with higher odds of clinical improvement at day 14 by $44.7 \%$ compared to placebo. The systematic review of Yokoyama et al. (23) also suggests that remdesivir had more clinical improvement at day 14 than standard treatment, which is consistent with the results of the present study. Data analysis of Jiang et al. (2020) resulted in similar findings (24). Some studies have also shown that remdesivir reduces time to clinical improvement $(12,13)$, which can reduce the length of hospital stay for patients, especially those admitted to the ICU (25).

An open-label, randomized, multicenter, phase III trial study confirmed that a 5-day remdesivir period was more effective than 10-day in clinical improvement (26). In another systematic review of remdesivir and its antiviral activity against COVID19, including in-vitro, in-vivo, emergency use in hospitals, and clinical trials, Frediansyah et al. (27) 
reported varied results for different types of studies. They revealed inhibitor effects of remdesivir on SARS-CoV-2 replication, reducing in viral load, and protective effects on infected animals with SARS$\mathrm{CoV}-2$. In addition, this study found that remdesivir reduces the pathological process, alleviates mild symptoms, and improves pulmonary lesions in the infected animals. Furthermore, in case of emergency use of remdesivir in hospitals, this systematic review found that some patients showed improved clinical outcomes. In contrast, in a clinical trial conducted in China, treatment with remdesivir demonstrated poor clinical benefits in terms of significant reductions in time clinical improvement and mortality (13).

The remdesivir application results determined that there were no significant differences in the risk of all adverse events (e.g., hypoalbuminemia, hypokalaemia, anemia, thrombocytopenia, increased total bilirubin, nausea, and headache) among patients receiving remdesivir and placebo/control. In this regard, Juul et al. (2020) reported similar results (1). On the other hand, Wang's study (21), which was performed based on two studies conducted by Beigel and Wang, founded that the risk of adverse events for remdesivir was significantly lower than the placebo/control. Izcovich et al. (2020) also stated that remdesivir might have negligible effects on acute kidney injury and cognitive dysfunction/delirium (28).

According to the results, remdesivir was safe in terms of the occurrence of serious adverse events (e.g., respiratory failure or acute respiratory distress syndrome, cardiopulmonary failure, pulmonary embolism, and recurrence of COVID-19). The above finding was consistent with the results of the study of Juul et al. (5). Regarding the serious adverse event, the findings of sensitivity analysis showed that excluding unpublished study had no significant changes in the achieved results related to safety of remdesivir.

\section{LIMITATIONS}

Our systematic review and meta-analysis have several limitations. First, although STROBE and CONSORT checklists were used for quality assessment of cohort and RCT studies, they only act as checklists that did not calculate the risk of bias assessment. Second, since the number of studies included in the meta-analysis was limited, the cohort and RCT studies were combined depended on type of outcome. Third, one of the studies (19) involved in the meta-analysis was not published in all journal (only a summary of results was reported). This issue could greatly affect study results. It should be noted that the inclusion and exclusion of the latter study had no significant effects on the overall sensitivity analysis. Forth, mortality rates reported in different studies were based on a different range of patients with various COVID-19 states. For example, some studies evaluated patients with severe COVID-19 and some studies patients with moderate COVID-19. Fifth, since remdesivir is not a dedicated medicine for the treatment of COVID-19 and studies on the safety and efficacy of this drug have been performed in a short period, it may cause various effects and adverse effects in the long term that requires future research. Sixth, although our results showed that remdesivir had no significant effect on mortality, clinical significance can also be important for interpreting and judging the results. Accordingly, due to the limitations of the present study, the results should be interpreted with caution.

\section{CONCLUSION}

Although remdesivir had no effects on all adverse events and mortality at day 14 of the treatment, it led to a reduction in serious adverse events and an increased clinical improvement than the placebo/control group.

\section{CONFLICTS OF INTEREST}

The author reports no conflicts of interest in this work.

\section{FUNDING}

This study was financially supported by Deputy of Research and Technology affiliated with Kerman University of Medical Sciences with grant number 99001039.

\section{ETHICS APPROVAL}

Approved by the Ethics Committee of Kerman University of Medical Sciences (No. IR.KMU.REC.1399.632). 


\section{REFERENCES}

1. Juul S, Nielsen EE, Feinberg J, Siddiqui F, Jørgensen CK, Barot E, et al. Interventions for treatment of COVID-19: A living systematic review with meta-analyses and trial sequential analyses (The LIVING Project). PLOS Medicine. 2020;17(9):e1003293. DOI:10.1371/journal.pmed.1003293

2. Dyer O. Covid-19: Mall poor countries will see almost no vaccine next year, aid groups warn. 2020;371:m4809. DOI:10.1136/bmj.m4809

3. Verdugo-Paiva F, Acuna MP, Sola I, Rada G. Remdesivir for the treatment of COVID-19: A living systematic review. Medwave. 2020;20(11):e8080.

DOI:10.1101/2020.09.27.20202754

4. Abeldano Zuniga RA, Coca S, Abeldano G, Gonzalez Villoria RAM. Clinical effectiveness of drugs in hospitalized patients with COVID-19 infection: a systematic review and meta-analysis. 2020. DOI:10.1101/2020.09.11.20193011

5. Gottlieb RL, Nirula A, Chen P, Boscia J, Heller B, Morris $\mathrm{J}$, et al. Effect of Bamlanivimab as Monotherapy or in Combination With Etesevimab on Viral Load in Patients With Mild to Moderate COVID-19: A Randomized Clinical Trial. JAMA. 2021;325(7):632-44.

DOI:10.1001/jama.2021.0202

6. Kim MS, An MH, Kim WJ, Hwang T-H. Comparative efficacy and safety of pharmacological interventions for the treatment of COVID-19: A systematic review and network meta-analysis. PLoS medicine. 2020;17(12):e1003501-e.

DOI:10.1371/journal.pmed.1003501

7. National Institutes of Health. Therapeutic Management of Patients with COVID-19. [Accessed 20 April 2021, Available from: https://www.covid19treatmentguidelines.nih. gov/therapeutic-management/].

8. Md Insiat Islam R. Current Drugs with Potential for Treatment of COVID-19: A Literature Review: Drugs for the Treatment Process of COVID-19. Journal of Pharmacy \& Pharmaceutical Sciences. 2020;23(1):58-64. DOI:10.18433/jpps31002
9. Padhy BM, Mohanty RR, Das S, Meher BR. Therapeutic potential of ivermectin as add on treatment in COVID 19: A systematic review and meta-analysis: Ivermectin in COVID-19: A meta-analysis. Journal of Pharmacy \&amp; Pharmaceutical Sciences. 2020;23:462-9. DOI:10.18433/jpps31457

10. Gilzad-Kohan H, Jamali F. Anti-Inflammatory Properties of Drugs Used to Control COVID19 and their Effects on the Renin-Angiotensin System and Angiotensin-Converting Enzyme2. Journal of Pharmacy \&amp; Pharmaceutical Sciences. 2020;23(1):259-77. DOI:10.18433/jpps31346

11. Siegel D, Hui HC, Doerffler E, Clarke MO, Chun K, Zhang L, et al. Discovery and Synthesis of a Phosphoramidate Prodrug of a Pyrrolo[2,1-f][triazin-4-amino] Adenine CNucleoside (GS-5734) for the Treatment of Ebola and Emerging Viruses. Journal of Medicinal Chemistry. 2017;60(5):1648-61. DOI:10.1021/acs.jmedchem.6b01594

12. Beigel JH, Tomashek KM, Dodd LE, Mehta AK, Zingman BS, Kalil AC, et al. Remdesivir for the Treatment of Covid-19 - Final Report. New England Journal of Medicine. 2020;383(19):1813-26.

DOI:10.1056/NEJMoa2007764

13. Wang Y, Zhang D, Du G, Du R, Zhao J, Jin Y, et al. Remdesivir in adults with severe COVID-19: a randomised, double-blind, placebo-controlled, multicentre trial. The Lancet. 2020;395(10236):1569-78. DOI:10.1016/S0140-6736(20)31022-9

14. Pan H, Peto R, Karim QA, Alejandria M, Henao-Restrepo AM, García $\mathrm{CH}$, et al. Repurposed antiviral drugs for COVID-19interim WHO solidarity trial results. New England Journal of Medicine. 2020;384(6):497-511.

DOI:10.1101/2020.10.15.20209817

15. Food and Drug Administration. Emergency Use Authorization - FDA. 2020. [Accessed 20 April 2021, Available from: https://www.fda.gov/media/137564/download ].

16. Gilead Sciences. Gilead Sciences Statement on The World Health Organization's Updated Veklury® (Remdesivir) COVID-19 Treatment Guidelines. [Accessed 20 April 
2021,

Available

from:

https://www.gilead.com/news-and-

press/compall-statements/gilead-sciences-

statement-on-updated-veklury-covid19-

treatment-guidelines].

17. Spinner CD, Gottlieb RL, Criner GJ, Arribas López JR, Cattelan AM, Soriano Viladomiu A, et al. Effect of Remdesivir vs Standard Care on Clinical Status at 11 Days in Patients with Moderate COVID-19: A Randomized Clinical Trial. JAMA - Journal of the American Medical Association. 2020;324(11):1048-57. DOI:10.1001/jama.2020.16349

18. Olender SA, Perez KK, Go AS, Balani B, Price-Haywood EG, Shah NS, et al. Remdesivir for Severe Coronavirus Disease 2019 (COVID-19) Versus a Cohort Receiving Standard of Care. Clinical Infectious Diseases. 2020. DOI:10.1093/cid/ciaa1041

19. Maffei D, Sonia C. Gilead Announces Results From Phase 3 Trial of Remdesivir in Patients With Moderate COVID-19, 2020 [Accessed 20 April 2021, Available from: https://www.businesswire.com/news/home/20 200601005310/en/].

20. Sarpatwari A, Kaltenboeck A, Kesselheim AS. Missed Opportunities on Emergency Remdesivir Use. JAMA. 2020;324(4):331-2. DOI:10.1001/jama.2020.11932

21. Wang M, Wu T, Zuo Z, You Y, Yang X, Pan L, et al. Evaluation of current medical approaches for COVID-19: a systematic review and meta-analysis. BMJ Support Palliat Care. 2020;11(1):45-52. DOI:10.1136/bmjspcare-2020-002554

22. Sarfraz A, Sarfraz Z, Sanchez-Gonzalez M, Michel J, Michel G, Frontela O, et al. Randomized controlled trials of remdesivir in hospitalized coronavirus disease 2019 patients: A meta-analysis. Turk J Emerg Med. 2021;21(2):43-50. DOI: $10.4103 / 2452-$ 2473.309139

23. Yokoyama Y, Briasoulis A, Takagi H, Kuno T. Effect of remdesivir on patients with COVID-19: A network meta-analysis of randomized control trials. Virus research. 2020;288:198137.

DOI:10.1016/j.virusres.2020.198137

24. Jiang Y, Chen D, Cai D, Yi Y, Jiang S. Effectiveness of remdesivir for the treatment of hospitalized COVID-19 persons: A network meta-analysis. Journal of medical virology. 2021;93(2):1171-4. DOI:10.1002/jmv.26443

25. Moitra VK, Guerra C, Linde-Zwirble WT, Wunsch H. Relationship Between ICU Length of Stay and Long-Term Mortality for Elderly ICU Survivors. Crit Care Med. 2016;44(4):655-62.

DOI:10.1097/CCM.0000000000001480

26. Goldman JD, Lye DCB, Hui DS, Marks KM, Bruno R, Montejano R, et al. Remdesivir for 5 or 10 Days in Patients with Severe Covid-19.

New England Journal of Medicine. 2020;383(19):1827-37.

DOI:10.1056/NEJMoa2015301

27. Frediansyah A, Nainu F, Dhama K, Mudatsir M, Harapan H. Remdesivir and its antiviral activity against COVID-19: A systematic review. Clin Epidemiol Glob Health. 2021;9:123-7.

DOI:10.1016/j.cegh.2020.07.011

28. Izcovich A, Siemieniuk RA, Bartoszko JJ, Ge L, Zeraatkar D, Kum E, et al. Adverse effects of remdesivir, hydroxychloroquine, and lopinavir/ritonavir when used for COVID-19: systematic review and meta-analysis of randomized trials. 2020. DOI:10.1101/2020.11.16.20232876 